\title{
Measuring Services and Tourism Convergence Among Five Old and Five New EU Member States
}

\author{
Borut Vojinovic ${ }^{1}$, Bostjan Brezovnik ${ }^{2}$, Zan Jan Oplotnik ${ }^{3}$ \\ ${ }^{1}$ University of Maribor, Faculty of Tourism \\ Cesta prvih borcev 36, SI-8250 Brezice, Slovenia \\ E-Mail.borut.vojinovic@um.si \\ ${ }^{2}$ University of Maribor, Faculty of Law \\ Mladinska ulica 9, SI-2000 Maribor, Slovenia \\ E-mail.bostjan.brezovnik@um.si \\ ${ }^{3}$ University of Maribor, Faculty of Economics and Business \\ Razlagova 14, SI-2000 Maribor, Slovenia \\ E-mail.zan.oplotnik@uni-mb.si
}

cross $^{\text {ref }}$ http://dx.doi.org/10.5755/j01.ee.27.3.11145

\begin{abstract}
The paper presents the analysis of the degree of convergence within two groups of countries analyzing Eurostat's Service Confidence Indicator - SCI indicator. In that matter we analyzed sigma $(\sigma)$ and beta $(\beta)$ convergences among the five European countries which accessed the European Union in 2004 and among five old EU member countries. In the context of analyzing services confidence convergence, and as a subdivision of services, we put a special focus on convergence in Tourism sector. By analyzing $\beta$ convergence we tested the volume of tourist arrivals and nights spent by tourists. Time series data for all selected variables covers the period between the years 2003 and 2011. Our results confirm that convergence of Service Confidence Indicator occurred in the service sector at the rate of 0,6\% during the whole analyzed period between the years 2003 and 2011 and 2,2\% and 0,9\% during the sub periods between the years 2003 and 2007 as well as in the sub period 2009 and 2011, respectively. We also found out that the group of EU-5 economies is converging towards the group of CEE-5 economies. Regarding the results of testing $\beta$ convergence for both selected variables in Tourism sector, no convergence was found, meaning that the initial volume of tourist arrivals and nights spent by tourists did not influence its growth rate over the period between the years 2003 and 2011.
\end{abstract}

Keywords: Convergence, EU, Tourism, Indicators, Business, Cycle.

\section{Introduction}

Certain role of consumer sentiment in theories of consumption behavior is not completely obvious. The classical theory for explaining household's consumption behavior is the life-cycle permanent income hypothesis (Friedman, 1957). The life-cycle permanent income hypothesis predicts that consumption depends on permanent income, which is the annuity of overall life time resources. It is theoretically implied that consumption is unrelated to current income, and if expectations are rational, consumption will follow a random walk (Hall, 1978). Thus, there will be no role for consumer confidence in predicting actual consumption. In accordance with Tijunaitiene et al., motivation happens to be the system of stimulation of behavior caused by different motives (Tijunaitiene et al., 2009). Empirical research results found positive relation between the consumption and current income, which consequently leads to a rejection of the life-cycle permanent income hypothesis in its purest form. To explain this deviation from the life-cycle permanent income hypothesis, some modification of its original form has been put forward. The process of communication, content creation, attraction of consumers, maintenance of communication reflects communication between business organizations and consumers (Zailskaite-Jakste \& Kuvykaite, 2012) According to the model of Campbell and Mankiw (Campbell \& Mankiw, 1989) some households are strict life-cyclers, while others follow a "rule of thumb" and let their spending equal to current income. Campbell and Mankiw claim that their model leaves room for consumer sentiment to predict spending through the income channel. However, the question about uncertainty arises. So called uncertainty hypothesis argues regarding the rate of uncertainty of consumers in the direction of higher (level) of uncertainty, i.e. more short term predictions can be expected, and hence they are less likely to show life cycle behavior. A large drop in current income would increase uncertainty and the need for precautionary savings, thereby lowering consumption. Positive correlation between current income and consumption, which increases with uncertainty, was developed by Blanchard and Mankiw (Blanchard \& Mankiw, 1988). With using uncertainty as a parameter, consumer sentiment may, therefore, also be useful for predicting spending.

Overall, these theories leave very little or hardly any room for sentiment to play any significant role in determining consumption. From the empirical point of view, the literature has investigated the extent to which confidence indicators can contain information regarding economic fundamentals that could be helpful to forecast future consumption. In that matter 
it is questionable if the wide range of sentiment and confidence indicators (e.g. Eurostat's group of Economic sentiment indicators) has a predictive power, on their own, for future changes in consumption and, whether they contain information regarding changes affecting consumption in the future and the information contained in other available indicators, such as unemployment, inflation or income. Authors have even argued that consumer sentiment simply reflects other economic determinants of private consumption (Shapiro, 1972). Once the appropriate underlying economic determinants have been identified and properly measured, there is no additional information value in consumer sentiment. However, in his work, Katona (1975) and later Salamon et al., (2015) question this view and claim that private consumption is determined by both the consumer's ability (disposable income and wealth) and willingness to pay. The latter, they argue, derive from complex psychological factors and cannot in a convenient way be explained by a simple measure, as income is (Salamon \& Mesko, 2016 and Salamon et al., in print). European commission (2008) defines that the movements in consumer sentiment usually capture changes in the frame of the will to pay. Therefore, consumer sentiment is not just a reflection of hard data, but captures something unique - of incremental importance - to consumption. Blanchard (1993) argues regarding the spontaneous fall in the US household consumption in the early 1990 's and claims that it was caused by households "animal spirits". The role of confidence indicators in economic analysis has been widely debated in the academic literature. In general there are two main approaches: so called Information view, which suggests that confidence indicators contain information about future economic situation, and the so called Animal spirits view, suggesting independent changes in beliefs have causal effects on business cycles. Both views (Information and Animal) are still compatible with leading indicator properties, but only the latter could imply certain extent of causality (Barsky \& Sims, 2012). On the other hand, it is empirically accepted that the conclusions remain ambiguous. Confidence and sentiment measures are shown to have at least some predictive power and a significant role in understanding business cycle fluctuations but, some researchers conclude that the concept of confidence does not play any valuable role in macroeconomics. The development of cyclical indicators, both the general approach and the confidence (sentiment) indicator database, in its modern form can be placed to portfolio of business cycle indicators started by the National Bureau of Economic Research (NBER) in the first half of previous century. Economic theory explained the possibility that general market waves of optimism and pessimism can be important accelerators of business cycles. Data about economic agents' sentiment (as for example data on Economic Sentiment Indicator or Services confidence indicator) are providing information about mentioned optimistic or pessimistic views on future economic developments in terms of uncertainty, which usually has substantial implications for the real economy. How to determine, when weakness in the leading indicators represents a true signal of recession ahead rather than just an inconsequential data series? One way is to examine the depth, duration and diffusion of the leading indicators. In that matter it is useful to observe the length of the weakness, in the sense of "longer weakness the deeper it gets"; and usually more widespread it may become, the more likely a recession will occur. Mentioned The mentioned indicators can, however, be helpful in discovering people's and managers' opinions on future economic developments. These indicators are timely and include information that is known by the survey respondents but not yet reflected in aggregate economic variables, such as consumption expenditures, employment or GDP. They base on personal views or the sentiments of individuals and they can reveal important information about expectations, particularly about the emergence of waves of optimism or pessimism that are shown to be important drivers of the business cycle.

Our statistical convergence analysis illustrates the usefulness of survey based confidence indicators for monitoring economic developments in the EU area and for identifying the emergence of waves of optimism and pessimism against the backdrop of the current crisis. Used measures and methodologies were applied from EU Directorate-General for Regional Policy (2008).In the frame of our analysis and as the objective of our analysis we assume that so called drivers of confidence and sentiment have at least some predicting power on "recognizing" future economic developments, therefore will discuss their movements in the context of convergence as the aim of our analysis. In this paper, we study the degree of convergence within two groups of countries analyzing Eurostat's Service Confidence Indicator (SCI) and $\beta$ convergence in Tourism sector (as a subdivision of Services sector). After first section, presenting the main concept of our paper, theoretical background of business cycles i.e. life cycle permanent income hypothesis and its implications, the rest of this paper is organized as follows. Second section presents convergence literature review, groups of analyzed countries and data series used. It is followed by section 3 presenting used methodology i.e. concepts of $\sigma$ and $\beta$ convergences. Section 4 presents our empirical findings and section 5 concludes the paper.

\section{Groups of Analyzed Countries and Data Series Used}

Regarding the past analysis of convergence, authors mainly analyzed economic growth and income and one of these earlier studies was processed by Baumol (1986), who argued that homogeneous groups of countries grew to converge towards a particular growth rate, while heterogeneous countries exhibited processes of divergence. Later on, empirical analyses on convergence were popularized by Barro (1991), Mankiw et al. (1992) and Barro and Sala-i-Martin (1991). Their work is based on two methods. The first was so called the Barro regression method - economic growth rate is regressed on the initial GDP level and other economic growth determinants. The other, representative is the Mankiw-Romer-Weil method, where economic growth rate is regressed on the initial income level and the variables which determine the steady state of a given country according to the Solow (1956) model. While the convergence analysis were implemented mainly in the field of economic growth and income, it is possible to say that empirical analyses on convergence of income for European countries began to appear in the late 1990s. Some of "uniformed" works are (Floyd \& Shinew,1999; Apostolakis, 2003; Kutan \& Yigit, 2004, 2005; Narayan, 2007; Vojinovic 
et al., 2009; Oplotnik et al., 2011; Abbott et al., 2012; Lin \& Huang, 2012). One can notice that these analyses vary substantially in their period of coverage, sample of countries, data and method, but authors generally agree that the new EU countries grew during the 1990s and 2000s in line with the neoclassical convergence hypothesis.

Analyzing economic convergence for the selected variables among several countries we formed two groups. Country groupings reflect certain attributes of the transition process as well as countries others geographical and historical aspects. First group is representing European countries (EU10) that accessed the European Union in 2004. This group includes 5 Central and Eastern European countries (CEE-5): the Czech Republic, Estonia, Hungary, the Slovak Republic and Slovenia. Common geographical and historical aspects relevant to transition countries are for this group already well recognized. In the second group are representatives of the old EU-15 member countries and includes 5 western European countries (EU-5): United Kingdom, Finland, Sweden, the Netherlands and Austria. Monthly data span from January 2003 to December 2011. In order to ensure the reliability and consistency of the data set employed, monthly data on Services confidence indicator (SCI) and the Tourism sector (tourist arrivals and nights spent by tourists), as a part of the Eurostat's statistics database, were compiled from the Business and consumer surveys monthly economic indicators statistics. According to EU Directorate General for Regional policy (2008) conducts regular harmonized surveys for different sectors of the economies in the EU and in the applicant countries.

The SCI data represents an arithmetic average of the balances (\%) referring to the questions on business situation of recent and expected evolution of demand. In accordance with Eurostat, the long term average refers to the period as from publishing the indicator up to present time. Data from Eurostat have been seasonally adjusted. For the purpose of further analysis, the countries are pooled in two logically differentiated groups. Further on, for the purposes of our analysis and used methodology, i.e. the concepts of $\sigma$ and $\beta$ convergences; we decided to introduce statistical scaling for centering the Eurostat's monthly data series for SCI on absolute value of hundred. If the indexes are higher than 100 we can conclude that the managers are forecasting better business/economic conditions and vice versa. There is a maximum of 108 observations. Given the focus of the paper, we also present the data on the analyzed variable for specific groups of countries in graphical form (Figures from 1 to 6).

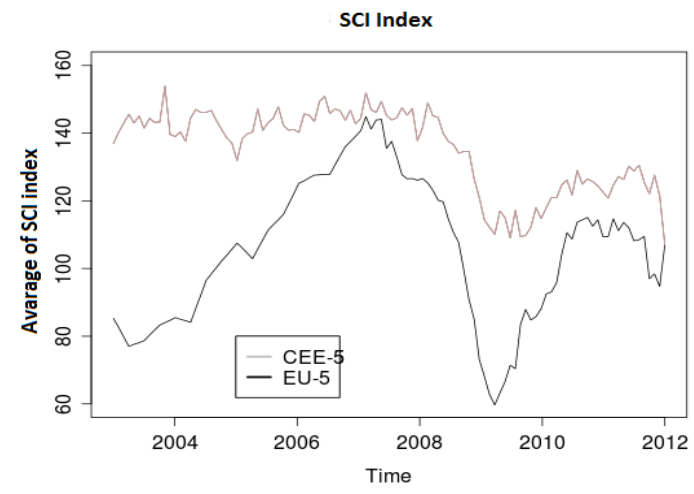

Figure 1. Time series of each group's average SCI index Source: Own calculation on Eurostat database

\section{Testing for $\Sigma$ and B Convergence}

For a more formal statistical test, we applied two generally excepted measures of convergence i.e.: $\sigma$ and $\beta$ convergence. $\sigma$-convergence measures whether or not analyzedanalysed variables have become more similar over time when compared to each other. On the other hand, $\beta$ convergence measures the speed with which analyzed variables tend to move in the same direction i.e. converge. Both measures are complementary and can provide differing insights. As already mentioned in the introduction of our paper, used measures and methodologies were applied from EU DG for Regional Policy (2008). In general we analyze $\beta$ convergence among the five of EU-10 countries for the January 2003 to December 2011 statistical data series. In order to test the sensitivity of the results on convergence, we divided statistical data series to three sub-periods: January 2003-February 2007, March 2007-March 2009 and April 2009-December 2011. The subdivision of the whole 2003 2011 period was made for SCI variable to statistically stress the fact of world financial crisis occurrence in our second sub period. The third sub period covers the years when first occurrences and crisis stresses were diminished at list to some extent.

\section{ß Convergence}

$\beta$ convergence refers to so called "catch up" process in which indicators of countries that are lower grow faster than high ones and therefore catch up on them. The concept of $\beta$ convergence is directly related to neo-classical growth theory (Solow, 1956). When all economies are assumed to converge towards the same steady-state, $\beta$ convergence is said to be absolute. However, the steady-state may depend on features specific to each economy, in which time convergence will still take place, but not necessarily at the same long-run levels. $\beta$ convergence is then said to be conditional. The methodology used to measure $\beta$ convergence generally involves estimating a growth equation in the following form:

$$
\begin{aligned}
& \log y_{i, t}=\propto+(1-\beta) \log y_{i, t-1}+\gamma X_{i, t}+\varepsilon_{i, t}, \\
& \operatorname{or}\left(\frac{y_{i, t}}{y_{i, t-1}}\right)=\propto-\beta \log y_{i, t-1}+\gamma X_{i, t}+\varepsilon_{i, t}, \\
& \text { where: }
\end{aligned}
$$

- $y_{i, t}$ is the growth rate of indicators in region at time $t$;

- $\mathrm{X}_{\mathrm{i}, \mathrm{t}}$ includes all other factors supposedly affecting the growth rate;

- $\varepsilon_{\mathrm{i}, \mathrm{t}}$ is the standard error term and $\alpha, \beta$ and $\gamma$ are the parameters to be estimated.

A negative relationship between the indicators growth rate $\left(\frac{y_{i, t}}{y_{i, t-1}}\right)$ and the initial level indicators $y_{i, t-1}=0$, i.e. 0 $<\beta<1$ is significant, is the sign of a convergence process. Since it is assumed that the economies do not differ significantly in their levels of investment ratio, industrial structure, technology and, human capital qualification and other structural factors, we set $X_{i, t}=0$ for all $t$ and for all $i$.

\section{$\sigma$ Convergence}

Since $\beta$ convergence is focusing on possible catching-up processes, on the other hand $\sigma$ convergence refers to a reduction of disparities among regions in time. The two 
concepts are of course closely related. Formally, $\beta$ convergence is necessary but not sufficient for $\sigma$ convergence. Intuitively, this is because economies can converge towards one another but random shocks push them apart. The sample variance of $\log$ indicators in $t$ is given by:

$$
\sigma_{t}^{2}=\frac{1}{N} \sum_{i=1}^{N}\left(\log y_{i, t}-\mu_{t}\right)^{2},(3)
$$

where $\mu_{t}$ is the sample mean of log indicators. When $N$ is large the sample variance is close to the population variance and we can derive:

$$
\sigma_{t}^{2}=(1-\beta)^{2} \sigma_{t-1}^{2}+\sigma_{\mu}^{2},(4)
$$

This difference equation is stable only if $0<\beta<1$. So $\beta$ convergence is necessary for $\sigma$ convergence. The dispersion of indicators levels can be measured by standard deviation, variation, or the coefficient of variation (CV). In our analysis we use the coefficient of variation, which is given by:

$$
C V=\left(\frac{\sigma_{t}}{\mu_{t}}\right),(5)
$$

In order to verify the $\sigma$ convergence hypothesis, we estimate the trend line of the dispersion levels among countries:

$$
C V_{(y t)}=\alpha^{*}+\sigma t+\varepsilon_{t},(6)
$$

where $\alpha$ and $\alpha^{*}$ are parameters to be estimated and $\varepsilon_{t}$ is the error term which has mean zero, finite variance, and is independent over $t$.

\section{Empirical Findings \\ The $\sigma$ Convergence}

Tests for significance of the $\sigma$ coefficients are shown in Table 1, scatter plots including the regression line are shown in Figure 2. The results of $\sigma$ convergence for the CCE-5 and EU-5 countries for the period 2003-2011 are presented in
Table 1 and Figure 2. Table 1 presents linear regression model of sigma coefficients for SCI 2003-2011 data as well as the respective coefficient of variation. Figure 2 presents dependency graph between the coefficient of variation and time along with the trend line for the whole period 2003 2011. The data show that the EU countries revealed $\sigma$ convergence during 2003-2007 period. The differentiation in the managers' expectations between economies in general decreased over time. However, during the period between 2007 and 2009 the differentiation between the expectations among countries increased and we cannot talk about $\sigma$ convergence. The non-existent of $\sigma$ convergence is attributed with the global financial crisis, later interpreted as already mentioned, even as the concept of a global economic crisis. Significant financial crisis in some countries lasts even till today, causing non-existent of $\sigma$ convergence.

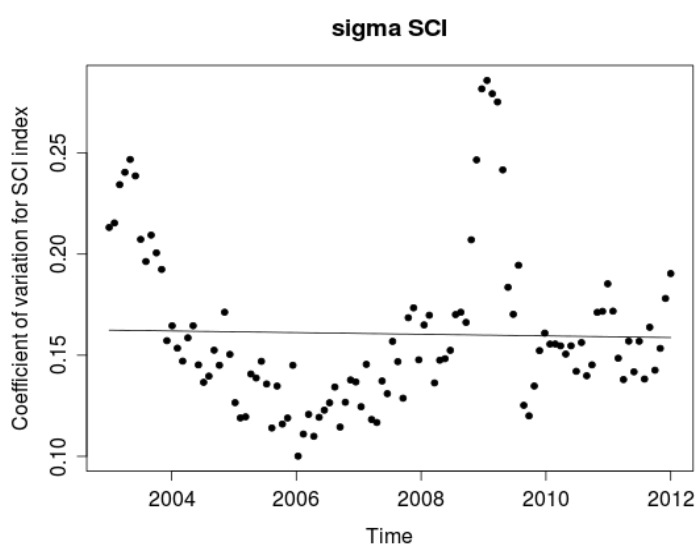

Figure 2. SCI $\sigma$ Convergence based on cross-sectional data 2003-2011

\begin{tabular}{|c|c|c|c|c|c|c|c|c|c|c|}
\hline & \multirow{3}{*}{$\begin{array}{r}\text { Intercept } \\
\text { Time }\end{array}$} & \multicolumn{2}{|l|}{ Estimate } & Std. Error & \multirow{2}{*}{$\begin{array}{r}\text { t-value } \\
0.333\end{array}$} & \multicolumn{2}{|c|}{$P R(>|t|)$} & & & \\
\hline & & 0.9771570 & & 2.9342692 & & & & & & \\
\hline & & -0.0004068 & & 0.0014617 & -0.278 & & & & & \\
\hline & & 2003 & 2004 & 2005 & 2006 & 2007 & 2008 & 2009 & 2010 & 2011 \\
\hline St. deviation & & 23.74 & 19.28 & 14.63 & 12.53 & 15.60 & 19.02 & 22.15 & 15.71 & 19.18 \\
\hline Mean & & 111.40 & 117.19 & 115.59 & 125.16 & 125,24 & 115.29 & 77.50 & 101.04 & 111.63 \\
\hline$\sigma$ coefficient & & 0.21 & 0.16 & 0.12 & 0.10 & 0.12 & 0.16 & 0.28 & 0.15 & 0.17 \\
\hline
\end{tabular}

Source: Own calculation on Eurostat database

Table 1

Linear regression model of sigma coefficients for SCI 2003-2011 data

\section{The Absolute $\beta$ Convergence}

As discussed in the previous section, we didn't reveal $\sigma$ convergence for the whole period. In that matter it is necessary to put in light again, with the applicative explanation, that $\beta$ convergence is a necessary but not the sufficient condition for $\sigma$ convergence. It is possible that the countries reveal $\beta$ convergence but not $\sigma$ one. We explain mentioned necessity and sufficiency condition(s) with analyzing $\sigma$ and $\beta$ convergence of GDP per capita at PPP. Firstly, if a poor country grows faster than a rich country ( $\beta$ convergence) and exceeds the income level of a rich country, the differences between countries need not to diminish (no $\sigma$ convergence). Second, if GDP in a poor country is $1 \$$ and in a rich country it is $1,000,000 \$$ and the poor country grows at the rate of 50 $\%$ and the rich country at the rate of $40 \%$ ( $\beta$ convergence), the new income levels are: $1.5 \$$ and $1,400,000 \$$, so the income differences are greater (no $\sigma$ convergence). As already mentioned in the previous section, we tested convergence in relation with the current economic crisis, thus we divided statistical data series to three sub-periods: January 2003February 2007, March 2007-March 2009 and April 2009December 2011. The results for $\beta$ convergence for the whole period as well as three distinguished "sub-periods are presented in Figures 3-6 and Tables 2-5.

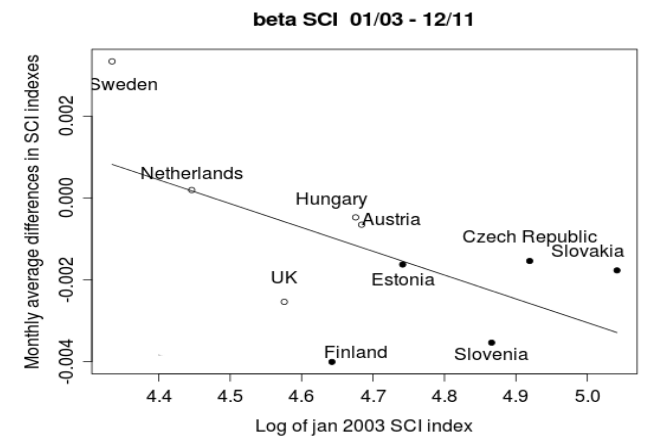

Figure 3. Absolute $\beta$ Convergence based on cross-sectional data, 2003-2011

Source: Own calculation on Eurostat database 
Linear regression model of beta coefficients of SCI 2003-2011 data

\begin{tabular}{|c|c|c|c|c|c|}
\hline & Estimate & Std. Error & t-value & & \\
\hline Intercept & 0.026050 & 0.013008 & 2.003 & 0.0802 & \\
\hline $\mathbf{x}$ & -0.005820 & 0.002769 & -2.102 & 0.0688 & \\
\hline Significance: & $0^{\prime} * * * ;$ & 0.001 '**, & $0.01^{\text {' } * \text {, }}$ & $0.05^{\prime}$, & $0.1^{\prime}$, \\
\hline
\end{tabular}

Residual standard error: 0.001775 on 8 degrees of freedom

Multiple R-squared: $0.3557 \quad$ Adjusted R-squared: 0.2752

F-statistic: 4.417 on 1 and $8 \mathrm{DF} \quad$ p-value: 0.06877

The existence of beta convergence was first tested graphically, where the logarithms of SCI index in the base year $(2003,2007$ or 2009) were shown on the X-axis and the monthly average differences of SCI indexes were shown on the y-axis.

We calculate $\beta$ coefficients from the regressions based on both cross-sectional and panel data. However, we have to emphasize that the $\beta$ coefficients are more accurate when they are based on cross-sectional data. Here, $\beta$ measures the absolute convergence (Vojinovic et al., 2009). In order to verify the absolute $\beta$ convergence hypothesis based on crosssectional data, we estimate regression in the form:

$$
\frac{1}{T} \log \left(\frac{y_{i, T}}{y_{i, 0}}\right)=\alpha_{0}+\alpha_{1} \log y_{i, 0}+\varepsilon_{i},(7)
$$

where $\log y_{t}$ and $\log y_{0}$ are the natural logarithms of SCI in country $i$ in the last and the first year of the period under analysis, respectively; $\alpha_{0}$ is a constant; $\varepsilon_{i}$ is the error term; and $T$ indicates the duration of the period. The number of years is actually $T+1$ because of the inclusion of both first and last year in the analysis.

In the case of conditional convergence, however, the values of $\beta$ may be overestimated. This is because in such regressions there are many explanatory variables and the coefficient on initial level of the monthly average differences in SCI indexes may have spuriously too high negative value. Even if this strong negative relationship is not spurious, the interpretation of $\beta$ coefficient in terms of the convergence of income has only a theoretical importance because the data used differences between economies do not necessarily diminish.

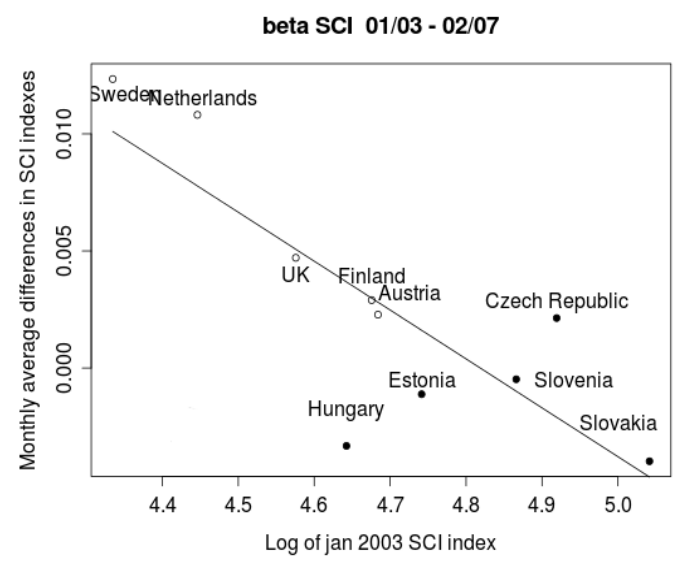

Figure 4. Absolute $\beta$ Convergence based on cross-sectional data, 01/2003-02/2007

Source: Own calculation on Eurostat database

Linear regression model of beta coefficients of SCI 01/2003-02/2007 data

\begin{tabular}{|c|c|c|c|c|c|}
\hline & Estimate & Std. Error & t-value & $P R(>|t|)$ & \\
\hline Intercept & 0.100601 & 0.024547 & 4.098 & $0.00345 * *$ & \\
\hline$t(x)$ & -0.020878 & 0.005226 & -3.995 & $0.00398 * *$ & \\
\hline Significance: & 0 '***' & 0.001 ***, & 0.01 '* & $0.05^{\prime} ?$ & 0.1 ، \\
\hline
\end{tabular}

Residual standard error: 0.00335 on 8 degrees of freedom

Multiple R-squared: $0.6661 \quad$ Adjusted R-squared: 0.6244

F-statistic: 15.96 on 1 and $8 \mathrm{DF}$ p-value: 0.003978

Firstly we tested the data for beta convergence for the whole period 2003-2012. Figure 3 indicates that the CEE5 countries have developed in line with the $\beta$ convergence hypothesis during the whole period analyzed 2003-2011. One can notice, from the graph in Figure 3 that the EU-5 and CEE-5 states lay nicely around the negatively slopped line. Furthermore the CEE-5 countries have higher starting point value while EU-5 countries are scoring lower. After calculating monthly averages differences in SCI indexes we came to the conclusion that the EU-5 countries seem to converge towards CEE- 5 countries, which can be explained with the more similar managers (representatives of the services sector) impressions on business situation, recent and expected evolution of the business situation, predictions regarding the "recognising" future economic developments and thus movement of our statistical values in the context of convergence.

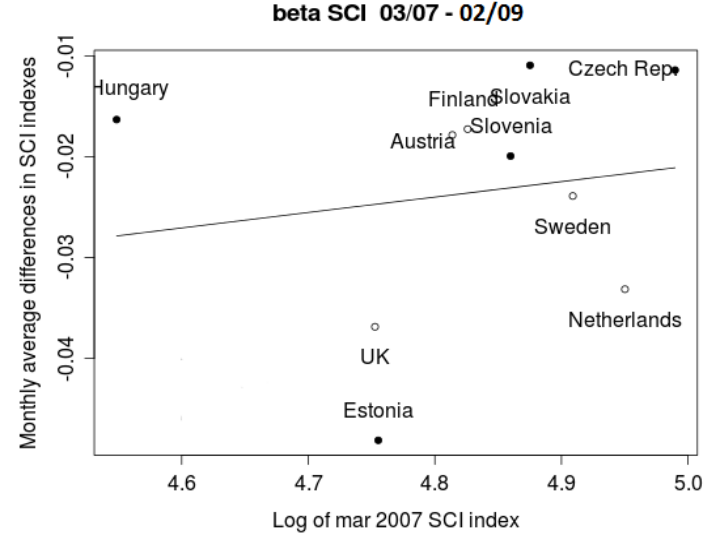

Figure 5. Absolute $\beta$ Convergence based on cross-sectional data, 03/2007-02/2009

Source: Own calculation on Eurostat database 
Linear regression model of beta coefficients of SCI 03/2007-02/2009 data

\begin{tabular}{|c|c|c|c|c|c|}
\hline & Estimate & Std. Error & t-value & $P R$ & \\
\hline Intercept & -0.09763 & 0.16354 & -0.597 & 0.567 & \\
\hline $\mathbf{t}(\mathbf{x})$ & 0.01534 & 0.03386 & 0.453 & 0.663 & \\
\hline Significance: & 0 ‘***, & 0.001 '**, & 0.01 '* & 0.05 ‘’ & $0.1^{\prime}$, \\
\hline \multicolumn{6}{|c|}{ Residual standard error: 0.01268 on 8 degrees of freedom } \\
\hline \multicolumn{3}{|l|}{ Multiple R-squared: 0.025} & \multicolumn{3}{|c|}{ Adjusted R-squared: -0.09687} \\
\hline \multicolumn{3}{|c|}{ F-statistic: 0.2051 on 1 and $8 \mathrm{DF}$} & \multicolumn{3}{|c|}{-value: 0.6626} \\
\hline
\end{tabular}

Let us give some explanations of our results. First sub period is indicated in Figure 4 and Table 3. We noticed clear $\beta$ convergence in the period before today's financial (economic) crisis. Figure 5 and Table 4 are representing second sub period. During this period the differentiation between the managers' expectations among countries increased and we cannot talk about $\beta$ - convergence during this period. The non-existence of $\beta$ convergence during the second period can be argument with the beginning of the global financial crisis i.e. first occurrences and crisis stresses, later interpreted as already mentioned, even as the concept of a global economic crisis.

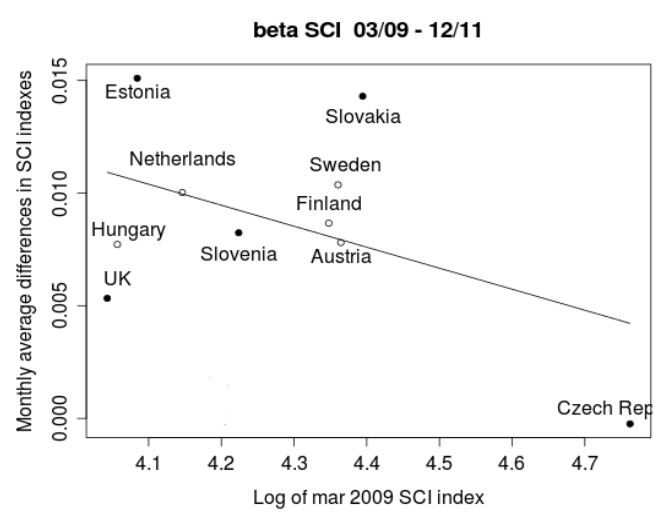

Figure 6. Absolute $\beta$ Convergence based on crosssectional data, 03/2009-12/2011

Source: Own calculation on Eurostat database

Linear regression model of beta coefficients of SCI 03/2009-12/2011 data

\begin{tabular}{|c|c|c|c|c|c|}
\hline & Estimate & Std. Error & t-value & $P R$ & \\
\hline Intercept & 0.048628 & 0.026646 & 1.825 & 0.105 & \\
\hline $\mathbf{t}(\mathbf{x})$ & -0.009325 & 0.006221 & -1.499 & 0.172 & \\
\hline Significance: & 0 ‘***, & $0.001^{\prime * * *}$ & 0.01 '* & $0.05^{\prime}$. & $0.1^{\prime}$, \\
\hline
\end{tabular}

Residual standard error: 0.004074 on 8 degrees of freedom

Multiple R-squared: $0.2193 \quad$ Adjusted R-squared: 0.1217

F-statistic: 2.247 on 1 and 8 DF $\quad$ p-value: 0.1722

Figure 6 and Table 5 are presenting again a clear development of $\beta$ convergence in line with the $\beta$ convergence hypothesis during analyzed third sub period, April 2009December 2011. Analyzed sub period belongs to the years when we can notice the results of crisis economic policies of EU member states governments as well as expansive policy provided by European central bank to encourage business sectors for achieving economic growth. The analysis based on cross-sectional data shows that the convergence accelerated over time: beta coefficient for the whole period was $0,6 \%$; for the sub-period 2007-2009 it equaled 2,2 \%, and for 20092011, 0,9 \% respectively. Moreover, the statistical tests regarding the significance of these differences, F-statistic and $\mathrm{p}$-value for testing the hypothesis on the equality of beta coefficients are presented in Tables 2 to 5 . Beta coefficients are calculated based on the regression coefficients using a logarithmic (i.e. nonlinear) transformation.

\section{Convergence in the Tourism Sector}

In the context of analyzing convergence of confidence in the services sector we concentrated especially on subdivision of services i.e. Tourism sector. In that matter we analyzed the hypothesis of $\beta$ convergence in the Tourism sector on the same sample of countries and for the same 2003-2011 time period as testing the convergence of SCI indicator in previous sections. The analysis includes two variables: tourist arrivals (both residents and non-residents) and nights spent by tourists (both residents and nonresidents). The second variable is more representative in terms of the Tourism sector development because it measures also the length of the stay and better accounts for the Tourism contribution in GDP. Data for the analysis was also derived from Eurostat database. To account for the fact that different countries have different size, the original Eurostat time series have been divided by the number of population to transform the data into per capita terms. 
Regression results for $\beta$ convergence of total tourist arrivals, 2003-2011

\begin{tabular}{lcccc}
\hline Model estimation & & & & \\
\hline & Estimate & Standard error & t-statistics & p-value \\
\hline Constant & 0,023032317 & 0,079659072 & 0,28913614 & 0,780 \\
logArrivals_2003 & $3,93099 \mathrm{E}-05$ & 0,016329607 & 0,00240728 & 0,998 \\
\hline R-squared & $7,24372 \mathrm{E}-07$ & F statistics & \multirow{2}{*}{ p-value for F } \\
Adj. R-squared & $-0,12499919$ & $5,79498 \mathrm{E}-06$ & 0,998138219 \\
Standard error & 0,024328293 & & & \\
No. Of observations & 10 & & &
\end{tabular}

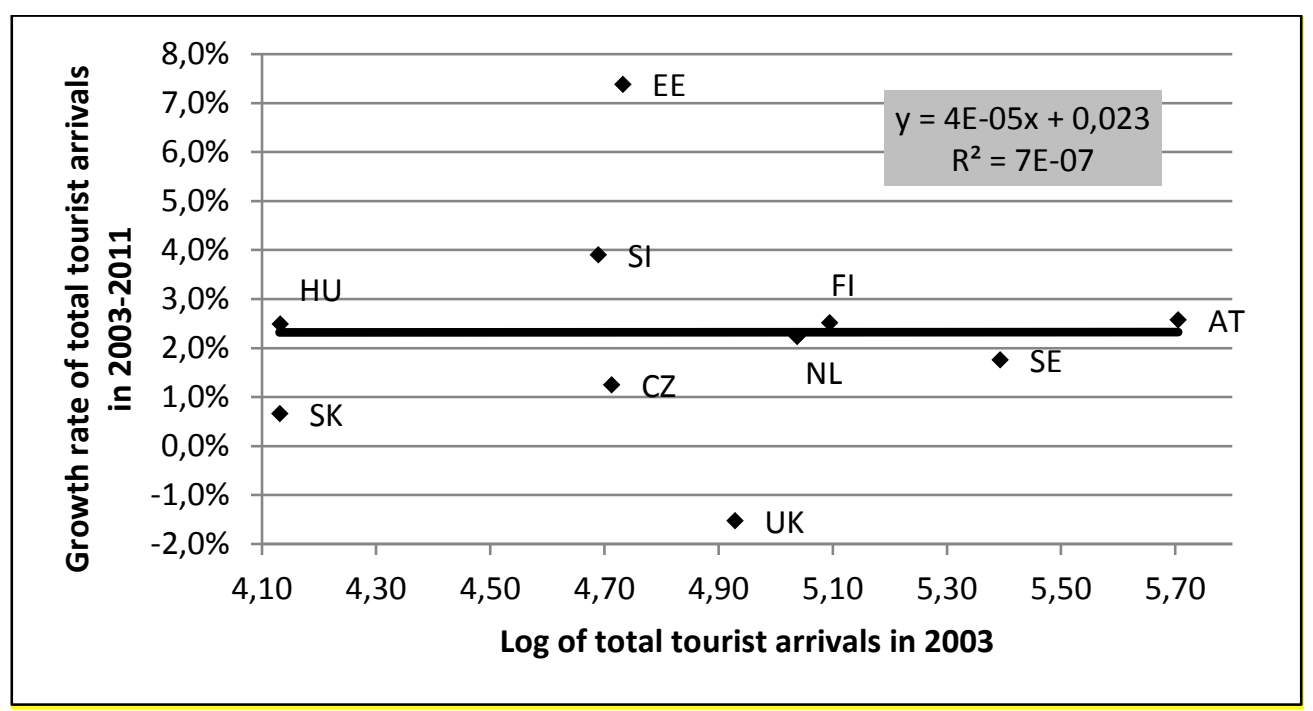

Figure 7. $\beta$ convergence of total tourist arrivals during 2003-2011 Source: Own calculation on Eurostat database.

In order to measure $\beta$ convergence, we compare the growth rate of a given variable during 2003-2011 and its initial level in 2003. The results are presented in Tables 6 and 7 and Figures 7 and 8 . The results given in Table 6 and Figure 7 indicate that there was no $\beta$ convergence in the number of total tourist arrivals among the ten examined EU countries. The regression line plotted in the figure is almost horizontal. Moreover, the distribution of individual points in many cases is far away from the trend line. It means that the initial volume of tourist arrivals did not influence its growth rate over the 2003-2011 period. As regards the second analyzed variable, i.e. the number of nights spent, the results indicate a negative relationship between the initial value and the subsequent growth rate. It is seen in Table 7 and Figure 8. However, $p$ value for the slope of the regression line stays at 0.537 indicating that a given variable is statistically insignificant. Hence, although a negative slope of the trend line, we cannot infer that there was $\beta$ convergence due to the fact that the estimated coefficient on the variable logNights_2003 turned out to be statistically insignificant. Hence, compared to the literature, despite evident income-level convergence in the EU (see e.g. Prochniak \& Witkowski, 2013, 2014), there was no convergence in the Tourism sector in the group of $10 \mathrm{EU}$ countries over 2003-2011.

Table 7

Regression results for $\beta$ convergence of total nights spent by tourists, 2003-2011

\begin{tabular}{lccc}
\hline Model estimation & & & \\
\hline & Estimate & Standard error & t-statistics \\
\hline Constant & 0,075260343 & 0,101194104 & 0,74372261 \\
logNights_2003 & $-0,010987379$ & 0,017052882 & $-0,6443122$ \\
\hline R-squared & 0,049332303 & F statistics: & 0,415138148 \\
Adj. R-squared & $-0,069501159$ & p-value for F & 0,537404688 \\
Standard error & 0,027301148 & & \\
No. Of observations & 10 & & \\
\hline
\end{tabular}




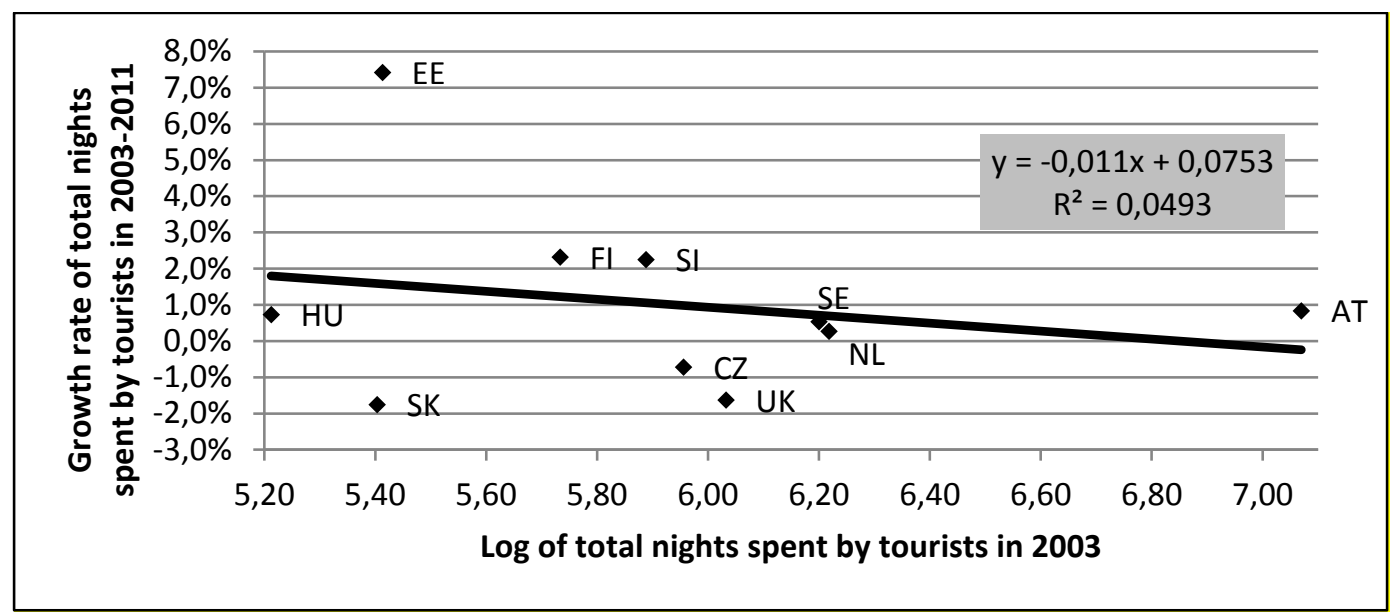

Figure 8. $\beta$ convergence of total nights spent by tourists during 2003-2011

Source: Own calculation on Eurostat database.

\section{Conclusions}

To some extent indicator analysis can be useful in providing earlier signals of the future economic movements that can reliably be found by using other analytical approach. Business cycle analysis represents sign regarding the direction of the economy over a certain short period from six to twelve months. Analysis of the convergence of cyclical indicators and Tourism sector contains certain information's about common (EU) application of economic policies within certain groups of countries. As already mentioned, business cycle indicators have proven to be useful tools for analyzing alternating sequences of economic expansions and contractions known as business cycles. Indexes and/or indicators, as analyzed Services confidence indicator, the number of total tourist arrivals and nights spent by tourists, contribute to analyst ability to capture that the future expectations of economic movements can be predicted to a certain level. Analyzed SCI data show that the EU countries revealed $\sigma$ convergence during 2003-2007 period. The differentiation in the managers' expectations between economies in general decreased over time. However, during the period between 2007 and 2009 the differentiation between the expectations among countries increased and we cannot talk about $\sigma$-convergence. The non-existent of $\sigma$ convergence is attributed with the global financial crisis, later interpreted even as the concept of a global economic crisis. Significant financial crisis in some countries lasts even till today, causing non-existent of $\sigma$ convergence. Analyzed sub period belongs to the years when we noticed the results of crisis on economic policies of EU member states governments as well as expansive policy provided by European central bank to encourage business sectors for achieving economic growth. The analysis based on cross-sectional data shows that the convergence accelerated over time. Regarding the Tourism sector we compare the growth rate of a given variable during 2003-2011 and its initial level in 2003. There was no $\beta$ convergence in the number of total tourist arrivals among the ten examined EU countries. It means that the initial volume of tourist arrivals did not influence its growth rate over the analyzed period. As regards the second analyzed variable, i.e. the number of nights spent, the results indicate a negative relationship between the initial value and the subsequent growth rate. Although a negative slope of the trend line, we cannot infer that there was $\beta$ convergence due to the fact that the estimated coefficient on the variable logNights_2003 turned out to be statistically insignificant. Hence, compared to the literature, despite evident income-level convergence in the EU there was no convergence in the Tourism sector in the group of 10 EU countries over 2003-2011 time period. The nature of the convergence process and earlier studies about convergence both inform that the catching up process is generally unstable over time. It means that there is no guarantee that the past tendencies in the economy will be maintained in the future. In contrast, in the next years we may observe both convergence and divergence trends. Much depends on economic policies, the situation in the world economy, as well as the political stance in Europe and the world as a whole. It means that empirical studies on convergence should be continued in both directions. First it is necessary to monitor the convergence path in the coming years. Second, some more sophisticated econometric methods to analyze time stability of the catching up process in the past years are also needed.

\section{References}

Abbott, A., De Vita, G., \& Altinay, L. (2012). Revisiting the convergence hypothesis for tourism markets: Evidence from Turkey using the pairwise approach. Tourism Management, 33(3), 537-544. http://dx.doi.org/10.1016/j.tourman.2011.06.003

Apostolakis, A. (2003). The convergence process in heritage tourism. Annals of Tourism Research, 30(4), $795-812$. http://dx.doi.org/10.1016/S0160-7383(03)00057-4

Barro, R. J. (1991). Economic Growth in Cross-Section of Countries. The Quarterly Journal of Economics, $106(2), 407-443$. doi: $10.2307 / 2937943$.

Barro, R. J., \& Sala-i-Martin, X. (1991). Convergence, Journal of Political Economy, 100(2), 223-251. doi: 10.1086/261816.

Baumol, W. J. (1986). Productivity Growth, Convergence, and Welfare: What the Long-Run Data Show. American Economic Review, 76, 1072-10855. 
Barsky, R., \& Sims, E. (2012). Information, animal spirits, and the meaning of innovations in consumer confidence. American Economic Review, 102, 1343-1377. doi: 10.1257/aer.102.4.1343

Blanchard, O. \& Mankiw, N. G. (1988). Consumption: Beyond Certainty Equivalence. American Economic Review, 78(2), 17377.

Blanchard, O. (1993). Consumption and the Recession of 1990-1991. American Economic Review, 83(2), $270-74$.

Campbell, J., \& Mankiw, G. (1989). Consumption, Income and Interest Rates: Reinterpreting the Time Series Evidence. NBER Chapters, in: NBER Macroeconomics Annual 1989, 4. doi: 10.2307/3584973

EU Directorate General for Regional Policy (2008). Convergence of EU regions, Measures and evolution No.1.

European Commission (2008). Key indicators for the euro area.

Floyd, M. F., \& Shinew, K.J. (1999). Convergence and divergence in leisure style among whites and African Americans: Toward an interracial contact hypothesis. Journal of Leisure Research, 31(4), 359-384.

Friedman, M. (1957). A Theory of the Consumption Function. Princeton University Press.

Hall, R. E. (1978). Stochastic implications of the life cycle-permanent income hypothesis. Journal of Political Economy 86(6), 971-87. doi: 10.1086/260724

Katona, G. (1975). Psychological Economics. New York, Elsevier Scientific Publishing Company. doi: 10.1016/S00905720(76)80015-0

Kutan, A. M., \& Yigit, T. M. (2004). Nominal and Real Stochastic Convergence of Transition Economies. Journal of Comparative Economics, 32, 23-36. doi: 10.1016/j.jce.2003.09.008

Kutan, A. M., \& Yigit, T. M. (2005). Real and Nominal Stochastic Convergence: Are the New EU Members Ready to Join the EuroZone?, Journal of Comparative Economics, 33, 387-400. http://dx.doi.org/10.1016/j.jce.2005.03.001

Lin, P. C., \& Huang, H. C. (2012). Convergence in income inequality? evidence from panel unit root tests with structural breaks. Empirical Economics, 43(1), 153-174. http://dx.doi.org/10.1007/s00181-011-0482-z

Mankiw, N. G., Romer, D., \& Weil, D. N. (1992). A Contribution to the Empirics of Economic Growth. The Quarterly Journal of Economics, 107, 407-37. doi: 10.2307/2118477

Narayan, Paresh K. (2007). Testing convergence of Fiji's tourism markets; Pacific Economic Review, 12(5), $651-663$. http://dx.doi.org/10.1111/j.1468-0106.2007.00377.x

Oplotnik, Z. J., Vojinovic, B., \& Acharya, S. (2011). Cross Border Economic Convergence and EU Integration Process. Lex Localis. Journal of local self-government, 9 (2), 179-203. doi: 10.4335/9.2.181-205(2011)

Prochniak, M., \& Witkowski, B. (2013). Time Stability of the Beta Convergence among EU Countries: Bayesian Model Averaging Perspective. Economic Modelling, 30, 322-333. doi: 10.1016/j.econmod.2012.08.031

Prochniak, M., \& Witkowski, B. (2014). On the Stability of the Catching-Up Process Among Old and New EU Member States. Implications from Bayesian Model Averaging. Eastern European Economics, 52 (2), 5-27. doi: 10.2753/EEE00128775520201

Solow, R. M. (1956). A Contribution to the Theory of Economic Growth. The Quarterly Journal of Economics, 70(1), 65-94. http://dx.doi.org/10.2307/1884513

Shapiro, H. (1972). The index of consumer sentiment and economic forecasting: A reappraisal, in Strumpel, B., Morgan, J., \& Zahn, E. (Eds.), Human Behavior in Economic Affairs, Jossey-Bass, San Francisco, 373-396.

Salamon, T., Milfelner, B., \& Belak, J. (2015). Late Payments and Ethics of Management: Possible Solutions for Local Economies. Lex Localis - Journal of local self-government Annual Conference 2015, 13(3), 351-373 http://dx.doi.org/10.4335/13.3.351-373(2015)

Salamon, T., \& Mesko, M. (2016). Can an ethical work climate influence payment discipline?. Journal of industrial engineering and management, 9(1), 73-89. http://dx.doi.org/10.3926/jiem.1537

Salamon, T., Milfelner, B., \& Belak, J. (2017, in print). Late payments Explained by Ethical Cuture. Journal of East European Management Studies, 22(1).

Tijunaitiene, B., Neverauskas, B., \& Balciunas, S. (2009). Activation of Participation Motivation Directed towards Agents: A Conceptual Model. Inzinerine Ekonomika-Engineering Economics (1), 65-74.

Vojinovic B., Prochniak M., \& Acharya S. (2009). Convergence Analysis Among the Ten European Transition Economies, Hitotsubashi Journal of Economics, 50(2), 124-141.

Zailskaite-Jakste, L. \& Kuvykaite, R. (2012). Implementation of Communication in Social Media by Promoting Studies at Higher Education Institutions. Inzinerine Ekonomika-Engineering Economics, 23(2), 174-188. http://dx.doi.org/10. 5755/j01.ee.23.2.1550

The article has been reviewed.

Received in March, 2015; accepted in June, 2016. 